\title{
COMPARISON OF SERUM PROLACTIN LEVELS IN PATIENTS WITH ERECTILE DYSFUNCTION WITH AND WITHOUT TYPE 2 DIABETES MELLITUS
}

\author{
Javaid Hassan', Shafiq Ur Rehman², Inayat Shah ${ }^{3}$, Henna Salman², Zain UI Abideen ${ }^{4}$, Muhammad Irfan Shereen ${ }^{5}$ \\ 'Department of Physiology, Muhammad College of Medicine, Peshawar - Pakistan \\ 2Department of Physiology, Khyber Medical College, Peshawar - Pakistan \\ ${ }^{3}$ Department of Physiology, Khyber Medical University, Peshawar - Pakistan \\ ${ }^{4}$ Department of Physiology, Kohat Institute of Medical Sciences, Kohat - Pakistan \\ ${ }^{4}$ Sifat Ghayur Children Hospital, Peshawar - Pakistan
}

\begin{abstract}
Objective: To compare serum Prolactin levels in patients with erectile dysfunction (ED) with and without type-2 Diabetes Mellitus

Materials and methods: This cross-sectional descriptive study was conducted over 100 Diabetics and 100 non-Diabetics patients with ED and their serum Prolactin levels were measured in all and compared in 2 groups. A convenience sampling technique was used to select patients from two Hospitals, i.e, Khyber teaching hospital Peshawar and Government Naseerullah Babar hospital, Peshawar. Independent sample t-test was performed for comparison between two groups.
\end{abstract}

Results: Serum Prolactin levels were high in diabetic patients with ED. Majority of patients were 40-49 years old. Duration of ED was higher in Diabetics patients as compared to Non-Diabetics.

Conclusion: ED is common in age group 40-49 years and in diabetics than in non-diabetics and is associated with high levels of serum Prolactin levels respectively. The duration of ED was also found to be more in diabetics than non-diabetics.

Keywords: Erectile Dysfunction, Serum Prolactin.

This article may be cited as: Hassan J, Rehman SU, Shah I, Salman H, Abideen ZU, Shereen MI. Comparison of Serum Prolactin levels in Patients with Erectile dysfunction with and without Type 2 Diabetes Mellitus. J Med Sci 2021 January;29(1):6-9

\section{INTRODUCTION}

Prolactin was first discovered by Stricher and Giveter in 1928. It is a protein of molecular weight 23,000 D. Normally the values in blood do not exceed $20-25 \mathrm{ng} /$ $\mathrm{ml}$. It is secreted by the mamotrofa cells of the Anterior Pituitary. The secretion is under the control of hypothalamic factor called the Prolactin inhibitory factor ${ }^{1}$.

Prolactin is produced in man in several other tissues like brain, mammary gland, lymphocytes, spleen and thymus. In reproduction, there is negative correlation between sperm and Prolactin levels. Hyperprolactinemia

\section{Correspondence}

Dr. Javaid Hassan

Department of Physiology, Muhammad College of

Medicine, Peshawar - Pakistan

Email: javidhassan1959@gmail.com

Cell: +92-305-9013700

Date received: $30-11-2020$

Date revised: $15-01-2021$

Date accepted: 14-03-2021 prevents Gonadotropin secretion affecting testicular functions $^{2}$. ED, previously called impotence, is defined as the condition in which there is failure to achieve or maintain a rigid penile erection for successful sexual intercourse. It is said that in about $50 \%$ infertilities, the causative factors belong to male $^{3}$. Diabetes Mellitus type- 2 is commonly associated with ED and may be a factor related to $E D^{4,5}$. ED is commonly observed in adult men above 40 years of age both in both diabetics and non-diabetics ${ }^{6}$. It has been observed that there is an inverse relationship of serum prolactin with testicular hormones and sexual functions in males. This study is aimed to compare the serum prolactin in diabetic and non-diabetic population with ED. It will improve our understanding about the relationship of this hormone and may be a target of future research and therapies for this purpose.

\section{MATERIALS AND METHODS}

This cross-sectional descriptive study was con- 
Comparison Of Serum Prolactin Levels in Patients With Erectile Dysfunction With And Without Type 2 Diabetes Mellitus.

ducted over 100 Diabetics (of more than 1 year duration) and 100 non-Diabetics patients with ED and their serum Prolactin levels were measured in all and compared in 2 groups. A convenient sampling technique was used to select patients from two Hospitals, i.e. Khyber teaching hospital Peshawar and Government Naseerullah Babar hospital, Peshawar. Patients having age of 30-65 years in both groups were included in the study. Those with active comorbidities like renal failure, liver cirrhosis, malignancy and cardiac failure were excluded. Unmarried persons were also excluded from the study.

A detail proforma and consent form was prepared before carrying out the study. The information obtained from the patients included name, age, ethnicity, duration of ED and family history of the Diabetes. The study was approved by the ethical committee of KMU and also Khyber Medical College, Peshawar, and data collection approval was taken from the relevant heads of the 2 hospitals. For prolactin, the kit used was ARCHITECT Prolactin (Abbot Diagnostic Wiesbaden, Germany) kit, (Reference No. TK 76-25). Glycosylated hemoglobin and blood glucose level were calculated in case of Diabetics.

SHIM SCORE was used for grading the degree of ED. ED was categorized as "Severe ED with a score of 1-7, moderate ED with a score of 8-16, and mild ED with a score of $17-21^{7}$. Frequencies and percentages were calculated for Prolactin of hyperglycemic and normoglycemic groups. Data was analyzed using SPSS version 23. Independent sample t-test was performed for comparison between two groups.

\section{RESULTS}

Among the 2 groups, age-wise distribution is shown in table-1, where almost half of patients were seen with ages between 40-49 years. Figure 1 showns comparison of levels of serum prolactin in both groups which is more in diabetics than non-diabetics $(p=0.021)$. The severity of ED is shown in Table-2 in Non-Diabetic with ED (100 patients), where more than half of patients have mild ED. The severe and moderate forms of ED were noted approximately in equal frequency (23\% and $20 \%$ ).

The severity of ED is shown in Table-3 in Diabetic patients with ED where more than half of patients are in the mild ED group like the previous observation. It is worth noticing that the distribution of severity of ED is approximately similar in both the Diabetic and Non-Diabetic cases. This study also shows that the duration of carrying the burden of ED is higher for the Diabetic patients (see figure-2). In Diabetics, the duration of ED is 85.1225 .75 (months) and in case of Non-Diabetics, the duration is
44.1017 .34 (months). The difference between the two groups is significant (less than 0.05)

Table 1: Age-wise distribution of ED patients in both Groups (200)

\begin{tabular}{|c|c|c|}
\hline Age Group & Frequency & Percentage \\
\hline $30-39 y r s$ & 45 & 22.5 \\
\hline $40-49 y r s$ & 89 & 44.5 \\
\hline $50-59 y r s$ & 43 & 21.5 \\
\hline $60-65$ yrs & 23 & 11.5 \\
\hline
\end{tabular}

Table 2: Severity of ED in non-diabetic cases

\begin{tabular}{|c|c|c|}
\hline Age Group & Frequency & Percentage \\
\hline Data on Severity & Frequency & Percent \\
\hline Mild & 57 & $57 \%$ \\
\hline Moderate & 20 & $20 \%$ \\
\hline severe & 23 & $23 \%$ \\
\hline
\end{tabular}

Table 3: Severity of ED in Diabetic Patients

\begin{tabular}{|c|c|c|}
\hline Form of ED & Frequency & Percent \\
\hline Mild & 56 & $56 \%$ \\
\hline moderate & 23 & $23 \%$ \\
\hline severe & 21 & $21 \%$ \\
\hline
\end{tabular}

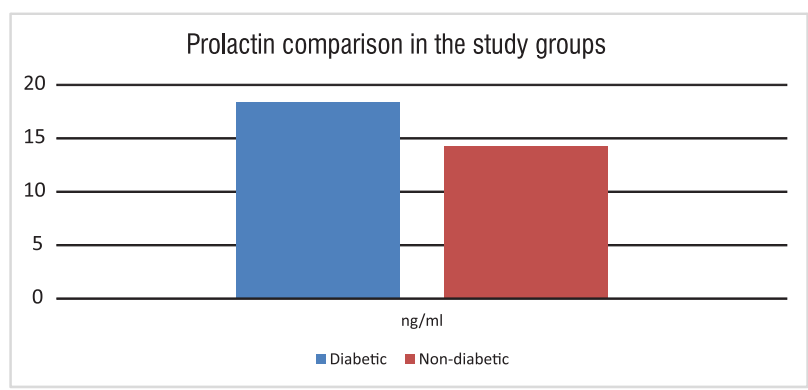

Fig 1: Prolactin comparison in the study groups

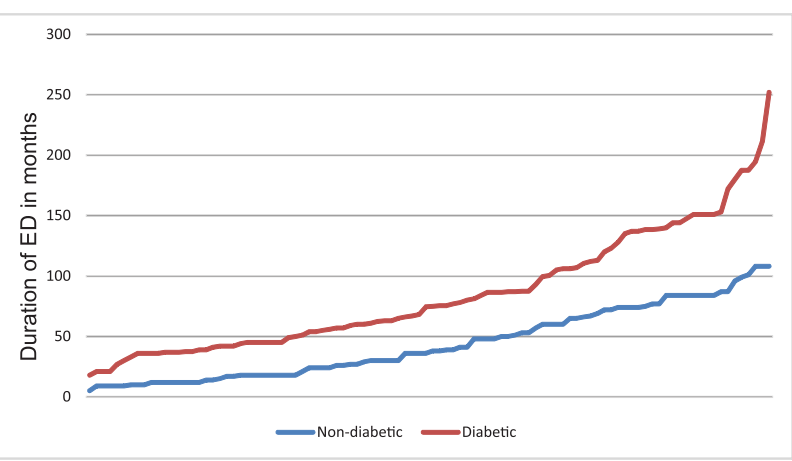

Fig 2: Duration of ED in diabetic vs Non-diabetic males

J Med Sci 2021anuary;29(1):7-9 
Comparison Of Serum Prolactin Levels in Patients With Erectile Dysfunction With And Without Type 2 Diabetes Mellitus.

\section{DISCUSSION}

Chronic hyperprolactinemia is found to be associated with decrease sexual desire in both genders ${ }^{8}$. Prolactin reduces the concentrations of sex hormones in blood. Gonadotropin releasing hormone secretion from the hypothalamus is reduced by the increased secretion of Prolactin from the Pituitary Gland. This lowers the secretion of Testosterone. This reduces the sexual desire and hence the chances of ED are increased ${ }^{9}$. In my study, we compared ED with serum Prolactin levels in Diabetic and Non-Diabetics. Concomitant with above fact, the Diabetic cases of our study showed a higher level of Prolactin than the Non-Diabetic cases. This is apparently due to diabetes affecting the autonomic and somatic nerves functions. Furthermore, Hyperprolactinemia prevent gonadotropin secretion affecting the testicular function ${ }^{10}$. In one of the study, hyperprolactinemia was noted in patients of Diabetes Mellitus type-2. Serum Prolactin levels were raised in $20 \%$ of control volunteers and $86.25 \%$ in those suffering from Diabetes Miletus type-2. It was also noted that Prolactin level were normal in $80 \%$ of control volunteers and $13.75 \%$ in Diabetics ${ }^{11}$. A Link could also be seen between high Prolactin levels and Insulin resistance in some studies $^{12}$. In our study, the most prevalent age for ED was 4049 years which is in contradiction to a Japanese and Australian study, where ED severity increased with increasing $\operatorname{age}^{13,14}$.

There is no information on how long the condition stays but our limited study suggested that ED stayed less longer (44 months on the average) in Non-Diabetic patients ${ }^{15}$. However, it is more prolonged when associated with Diabetes (averaged 85 months and counting). However, this duration is amid the ED and a proper follow up will lead to the duration in which the condition is resolved with medication, education, exercise and/or otherwise. For division of patients based on severity of ED, we have assorted the patients into these categories based on the sexual Health Inventory for Men (SHIM) score. My study has shown that there is no significant difference regarding the severity of the disease in Diabetic and Non-Diabetic group (P-value $>0.05$ ). This study, although limited to a single city and was hospital based, but still highlights the importance of ED as one of the important social and psychological factor in the management of diabetic patients. Further large scale studies are needed to highlight the relationship of ED with serum prolactin levels in different age and population groups.

\section{CONCLUSION}

ED is common in age group 40-49 years and in diabetics than in non-diabetics and is associated with high levels of serum Prolactin levels respectively. The duration of ED was also found to be more in diabetics than non-diabetics.

\section{REFERENCES}

1. Owiredu WK, Amidu N, Alidu H, Sarpong C, Gyasi-Sarpong CK. Determinants of sexual dysfunction among clinically diagnosed diabetic patients. Reproductive Biology and Endocrinology. 2011;9(1):70.

2. Neill J. Effect of "stress" on serum prolactin and luteinizing hormone levels during the estrous cycle of the rat. Endocrinology. 1970;87(6):1192-7.

3. Muneer A, Kalsi J, Nazareth I,Arya M, Erectile dysfunction. BMJ (Clinical research ed.) 2014 Jan 27; [PubMed PMID:24468580] Dupree JM. Insurance coverage of male infertility: what should the standard be? Transl Androl Urol. 2018;7:S310-S6. doi: 10.21037/tau.2018.04.25.

4. Furukawa S, Sakai T, Niiya T, Miyaoka H, Miyake T, Yamamoto $\mathrm{S}$, et al. Depressive symptoms and prevalence of erectile dysfunction in Japanese patients with type 2 diabetes mellitus: the Dogo Study. Int J Impot Res. 2017;29:57-60. doi: 10.1038/ijir.2016.45

5. De Berardis G, Pellegrini F, Franciosi M, Belfiglio M, Di Nardo B, Greenfield S, et al. Clinical and psychological predictors of incidence of self-reported erectile dysfunction in patients with type 2 diabetes. J Urol. 2007; 177:2527. doi: 10.1016/j.juro.2006.08.102.

6. Mehta A, Nangia AK, Dupree JM, Smith JF. Limitations and barriers in access to care for male factor infertility. Fertil Steril. 2016;105:1128-37. doi: 10.1016/j. fertnstert.2016.03.023.

7. Dupree JM. Insurance coverage for male infertility care in the United States. Asian J Androl. 2016;18:339-41. doi: 10.4103/1008-682X.177838

8. Shamloul R, Ghanem H. Erectile dysfunction. The lancet. 2013;38(9861):153-65.

9. Hull MG, Glazener CM, Kelly NJ, Conway DI, Foster PA, Hinton RA, et al. Population study of causes, treatment, and outcome of infertility. Br Med J (Clin Res Ed). 1985;291:1693-7. doi: 10.1136/bmj.291.6510.1693

10. Galdiero M, Pivonello R, Grasso L, Cozzolino A, Colao A. Growth hormone, prolactin, and sexuality. J endocrino investi. 2012;35(8):782-94. 
11. Zeitlin SI, Rajfer J. Hyperprolactinemia and erectile dysfunction. Reviews in urology. 2000;2(1):39.

12. Ludwig W, Phillips M. Organic causes of erectile dysfunction in men under 40. Urol Int. 2014;92(1):1-6. [PubMed]

13. World Medical Association. World Medical Association Declaration of Helsinki: ethical principles for medical research involving human subjects. Jama. 2013 Nov 27;310(20):2191-4.

14. Daimon M, Kamba A, Murakami H, Mizushiri S, Osonoi S, Yamaichi M, et al. Association between serum prolactin levels and insulin resistance in non-diabetic men. PLoS One. 2017;12:e0175204. [PMC free article] [PubMed] [Google Scholar]

15. Marumo K, Nakashima J, Murai M. Age-related prevalence of erectile dysfunction in Japan: Assessment by the International Index of Erectile Function. International journal of urology. $2001 \mathrm{Feb} ; 8(2): 53-9$.

16. Pinnock CB, Stapleton AM, Marshall VR. Erectile dysfunction in the community: a prevalence study. Medical Journal of Australia. 1999 Oct;171(7):353-7.

17. Utomo E, Blok B, Pastoor H, Bangma $\mathrm{CH}$, Korfage IJ. The measurement properties of the five item International Index of Erectile Function (IIEF 5): a Dutch validation study. Andrology. 2015;3(6): 1154-9.
CONFLICT OF INTEREST: Authors declare no conflict of interest

GRANT SUPPORT AND FINANCIAL DISCLOSURE: NIL

\section{AUTHOR'S CONTRIBUTION}

Following authors have made substantial contributions to the manuscript as under

Hassan J: Concept, study design, discussion, manuscript writing, facilitation of the reagent and materials, critical review

Reman SU: Facilitation of the reagent and materials, critical review, interpretation.

Shah I: $\quad$ Analysis, interpretation, manuscript writing, study conduction.

Salman H: Analysis, interpretation, manuscript writing, study conduction

Abideen ZU: Critical review, study conduction.

Shereen MI: Over all supervision

Authors agree to be accountable for all aspects of the work in ensuring that questions related to the accuracy or integrity of any part of the work are appropriately investigated and resolved. 